\title{
Electricity security in the European Union - the conflict between national Capacity Mechanisms and the Single Market
}

\author{
Graeme Hawker, Keith Bell, Simon Gill \\ Institute for Energy and Environment, Department of Electronic and Electrical Engineering, University of Strathclyde, Glasgow, United Kingdom \\ graeme.hawker@strath.ac.uk
}

\begin{abstract}
The European Single Market aims to promote trade and competition in electricity generation across the EU, with investment signals for new generation capacity and interconnection coming from zonal electricity prices reflecting scarcity value. However, a growing number of EU Member States have implemented national Capacity Mechanisms in order to ensure future security of supply within their own borders, which may distort the cross-border trade of energy. This local view of energy security is in response to internal technical and economic constraints and a perceived inability of cross-border electricity flows to be a reliable source of capacity at times of maximum stress, in favour of self-sufficiency. A number of routes are available to resolve this conflict through permitting cross-border participation of generators in local Capacity Mechanisms, but this requires resolution of a number of complicating factors, not least a means for properly allocating transmission capacity without introducing further distortions to the energy market. Alternative solutions could be enacted at an EU-level, such as through the alignment of Capacity Mechanisms to a common model, or the introduction of an EU-wide single Capacity Mechanism, but the current regulatory focus appears to remain on resolution of such issues at a national level.
\end{abstract}

Keywords: Energy security, Electricity transmission, Interconnection, Capacity Markets

\section{Introduction}

The creation of a secure electricity system creates a distinct set of planning constraints for governments and their agencies. The overriding political goal is, primarily, to create - through appropriate investment at sufficiently advanced timescales - a market and network capable of serving the future demands for electricity (whatever that may turn out to be) across all sectors. As secondary concerns, this must also be done at reasonable cost to the end consumer and, in keeping with constraints on greenhouse gases and other atmospheric pollutants, be achieved within decreasing emissions limits. These three objectives comprise what is classically termed the 'energy trilemma' (Ang, Choong, \& Ng, 2015), to which may be added the requirement for the social impacts of electricity investment to be fairly allocated, and for associated commercial structures to enable investment to be secured in a manner compatible with standard financial instruments.

(Jervis, 1978) presents the classical security dilemma of international politics: that many of the means by which a state tries to increase its security decrease the security of others. While the dilemma is originally posited in the context of Defence, the concept of the requirement for a collective security arrangement to be perceived as well-functioning by its member states (and even perhaps as a precondition to seeking membership of the arrangement) applies equally well to energy security. In the context of energy, states are highly interdependent; energy is vital to state survival, and can be used to harm other states leading to a complex intertwining of energy supply with geopolitics (Ciuta \& Ciută, 2010). Within the European Union, there has been a growing move towards energy interdependence within a framework of Market Liberalism, based on cooperation through non-discriminatory open markets available to foreign investment, enacted within the 'Single Market for Energy'. However, each individual Member State must balance its degree of cooperation against its own sovereignty in energy (McGowan, 2008).

As opposed to the general situation for energy, electricity is particular in that almost all countries possess the ability to be self-sufficient in terms of generation capacity, and to not be dependent on external imports (although conventional generation may be reliant on fuel imports). This means that each country broadly has the ability to determine its own electricity future according to its own technical and political situation, and to determine the extent to which it relies on cross-border trades in electricity to establish appropriate levels of electricity security. In recent years, the closure of conventional generators due to environmental regulations and the increasing penetration of renewable energy has led to increased concern over domestic levels of electricity security in Member States (RAP Energy Solutions, 2013). Additionally, many States have moved to support increasing localisation of energy systems in order to support diversity and security ( $\mathrm{Li}, 2005)$. This has led many States to implement Capacity Mechanisms in addition to their core energy wholesale markets in order to ensure ongoing security of supply and fill an expected capacity gap.

In turn, the decisions of one Member State in how it treats electricity security will affect the extent to which its neighbours may be reliant on it for imports at key times of system stress. This leads to a situation where the Single Market may not yet be trusted by all Member States to provide mutual electricity security, leading to the implementation of national Capacity Mechanisms, which in turn reduces the effectiveness of the Single Market in ensuring security. This maps back to the central idea of the security dilemma whereby a State's means of self-help - trying to escape from the dilemma by accumulating more and more local power generates a cycle of power competition (Tang, 2009). 
In this paper, we survey the evolution of cross-border trades in electricity in the EU; the current status of Capacity Mechanisms: where they have been implemented to date; the drivers for their implementation, and how this relates to the reality and perception of energy security; how Capacity Mechanisms have been incorporated into EU electricity regulation to date; the ongoing and future possible impacts on the efficient use of cross-border signals for generation investment; and, finally, how in the future these issues may be resolved at the European level.

\section{Development of EU Electricity Markets and Cross- border Exchanges}

The reform and deregulation of western electricity markets through the 1980s and 90 s included a restructuring of the generation sector to enable wholesale competition. Generation owners and operators would respond to price signals from centralised spot markets and/or bilateral trading with retailers, rather than investment in new generation being centrally planned and controlled.

This shift from central planning, however, also removed the ability of governments to ensure through direct means that sufficient generation would be in place to meet demand. A market-based mechanism for electricity removes the 'command and control' of monopoly generators which can ensure adequate capacity margins. However, this centralised planning can also lead to 'gold plating' of secure supplies by creating a greater capacity margin than is necessary (Helm, 2004) .

Under the market-led paradigm, spot markets for electricity should provide a complete price signal for sufficient investment in new generation capacity. If there is a perceived shortfall in capacity at some future horizon, it should also be evident to investors that there is a matched benefit in owning operating capacity at that point in time due to raised electricity prices reflecting that shortfall - in other words, scarcity pricing should stimulate new investment.

The 'missing money' problem, occurs, however, when conditions arise in markets which mean that the energy market alone does not provide sufficient (or sufficiently reliable) revenue for investment to occur. This may arise due to a number of factors, including (Newbery, 2015): low wholesale energy prices (which may be driven by high penetrations of renewable generation with negligible marginal costs); price caps below the Value of Lost Load (the economic cost impact of not supplying a consumer with their desired power demand); inefficiently high transmission charging; or inadequate remuneration for ancillary services. Similarly, there may be the 'missing market' problem where the revenue is in reality adequate but is not perceived to be so (Newbery, 1989).

Historically across Europe, transmission interconnections between national systems have been developed to promote security of supply, but increasingly have taken on a wider role in order to promote competition, trade and an increase in overall welfare across EU Member States (Jacottet, 2012). A shortage of interconnection capacity creates barriers to trade, and so the European Commission has been taking steps - most significantly through the Third Energy Package of 2009 (European Parliament, 2009) - to promote investment in new cross-border connections. The Energy Union package of 2015 refers to desirable levels of interconnection of $10 \%$ and $15 \%$ by 2020 and 2030 respectively, although there is no proposal for these targets to be mandatory (European Commission, 2015a). This underpins the European Internal Electricity Market (also known as the Single Market), which requires sufficient physical transmission links between member states to transmit demand,

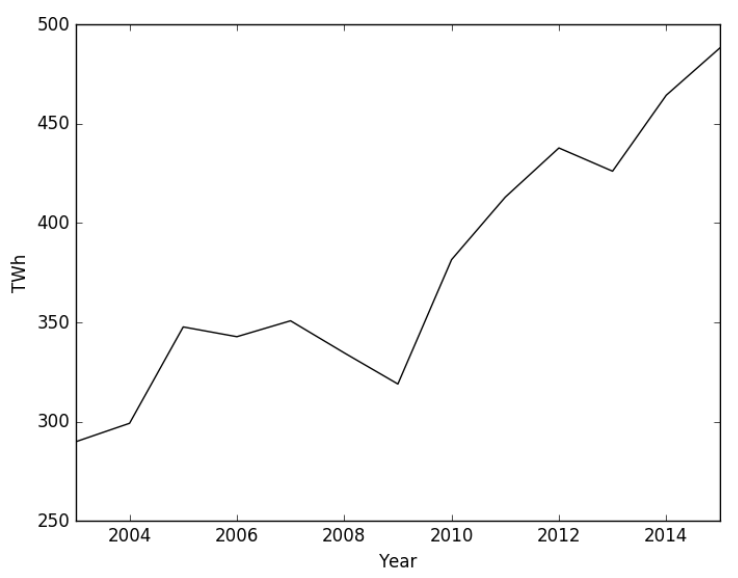

Figure 1 - increasing volumes of cross-border trades in energy between EU Member States since the Second Energy Package of 2003 (ENTSO-E, 2016)

and enough efficient market-based mechanisms to make the most of the transmission capacity. In pursuit of this aim, the Commission has been promoting a Target Model for electricity markets to facilitate border-free trading across Europe. The Target Model is based on two broad principles: energy-only regional markets, preferably organised on a zonal basis, in which generators' revenues depend primarily on the price for each marginal unit of energy supplied; and market coupling, which is a way of linking zonal day-ahead spot markets into a virtual market, so that the lowest priced bids are accepted up to the point where congestion constraints limit further trade (Keay, 2013). However, interconnector growth may be constrained by long lead times and capital investment costs in transmission infrastructure, as well as uncertainty on the part of investors that energy arbitrage will be sufficient in future to ensure longterm profitability (Turvey, 2006).

Figure 1 shows the increasing volumes of energy traded across Member State borders since the implementation of the Second Energy Package of 2003 which established the basic framework for market alignment (though it should be noted that not insignificant levels of energy have been traded across those borders for far longer through bilateral arrangements, and that the EU-wide framework has not been a pre-requisite for such trade).

In some EU Member States, there have been Capacity Mechanisms established - whereby electricity generators, interconnectors or demandside response providers receive some form of remuneration for being available to meet electricity demand irrespective of whether they actually are dispatched (either by the market or a central operator) to do so. These Mechanisms have been created in response to a perceived (or in some cases, actual) failure of the energy-only markets within those nations, and operating across borders between nations, to provide sufficient capacity to meet demand. The existence of these mechanisms may distort the wider price signals intended to underpin the European Single Market for electricity.

\section{Capacity Mechanisms in the EU}

A Capacity Mechanism may be defined as a measure taken by a state designed to support investment to fill an expected capacity gap and ensure 
security of supply. Typically, capacity mechanisms offer additional rewards to capacity providers, on top of income obtained by selling electricity on the market, in return for maintaining existing capacity or investing in new capacity needed to guarantee security of electricity supplies.

Table 1 - Current EU Capacity Mechanisms (European Commission, 2016; Hancher, de Hauteclocque, \& Sadowska, 2015; Linklaters, 2014).

\begin{tabular}{|c|c|c|}
\hline Market & Description & Year Implemented \\
\hline Great Britain & $\begin{array}{l}\text { Centralised annual capacity } \\
\text { auction }\end{array}$ & $\begin{array}{l}2014 \text { (as part of } \\
\text { Electricity Market } \\
\text { Reforms) }\end{array}$ \\
\hline Ireland & Capacity payments for availability & $\begin{array}{l}2007 \text { (as component of } \\
\text { the all-island Single } \\
\text { Electricity Market) }\end{array}$ \\
\hline Belgium & $\begin{array}{l}\text { Strategic reserve contracted by } \\
\text { Transmission System Operator }\end{array}$ & 2014 \\
\hline France & $\begin{array}{l}\text { Decentralised forward capacity } \\
\text { obligation on Suppliers delivered } \\
\text { through certificates }\end{array}$ & 2010 \\
\hline Nordic Countries & $\begin{array}{l}\text { Strategic reserves procured } \\
\text { through forward markets }\end{array}$ & 2003 \\
\hline Germany & $\begin{array}{l}\text { Contracted re-dispatch reserve } \\
\text { and winter reserve; a new } \\
\text { Capacity Reserve mechanism has } \\
\text { recently been approved }\end{array}$ & $\begin{array}{l}\text { 2012, new reforms } \\
\text { approved } 2016\end{array}$ \\
\hline Italy & $\begin{array}{l}\text { Temporary capacity payments; } \\
\text { centralised auctions for reliability } \\
\text { options are being developed for } \\
\text { implementation from } 2017 / 18\end{array}$ & $\begin{array}{l}2003 \text { (following } \\
\text { blackouts) }\end{array}$ \\
\hline Greece & $\begin{array}{l}\text { Capacity payments for availability } \\
\text { at peak load times }\end{array}$ & $\begin{array}{l}2006 \text { (as part of wider } \\
\text { market reforms } \\
\text { following blackouts in } \\
2004 \text { ) }\end{array}$ \\
\hline Spain & $\begin{array}{l}\text { Fixed capacity payments for } \\
\text { availability and new investment }\end{array}$ & 1997, reformed 2007 \\
\hline Portugal & Joined Spanish mechanism & 2010, abolished 2013 \\
\hline
\end{tabular}

The European Commission recognises six forms of Capacity Mechanism within two broad categories (European Commission, 2015b):

Targeted mechanisms, where support is given to additional capacity expected to be required on top of what is provided by the market:

- Tender: where a beneficiary of a tender receives public financing for the construction of a power plant;

- Reserve: where contracted capacity is held in reserve outside the market and only activated where necessary;

- Targeted capacity payment: where a price set by a central body is paid to a subset of capacity in the market (such as a specific technology type);

Market-wide mechanisms, where support is provided to all (or the majority of) providers of capacity in the market:
- Central buyer: where a volume of capacity required is set and a market determines the price at which this is provided through a central bidding process;

- De-central obligation: where an obligation is placed on market participants (such as retailers) to contract sufficient capacity to cover their demand;

- Capacity payment: A price for capacity expected to achieve sufficient investment is fixed, and the market responds with a variable volume.

There are currently 13 EU Member States with some form of implemented capacity payments, summarised in Table 1.

\section{Drivers for Implementation of Capacity Mechanisms}

In the case of Italy and Greece, the occurrence of blackouts (in 2003 and 2004 respectively) directly led to the implementation of capacity payments in order to bring new capacity rapidly to market and avert further such incidents. However, the remainder of national mechanisms are, instead, intended to avert future issues - and are driven by perceived (rather than proven) failures in energy-only markets to be able to maintain a secure system in the future, according to the national-level assessment of the level of capacity that may require. The drivers may broadly be divided into economic, technical and political categories, although with some overlap between these classifications. Each are discussed in turn below with reference to exemplar market implementations, representing different designs as described in Section 3.

\subsection{Economic Drivers}

Economic drivers include the 'missing money' problem described in Section 1 where energy market signals are themselves insufficient to either drive new investment capacity or to keep existing capacity operational; concerns over the market power held by individual actors where capacity margins are low; low profitability of (for example) gas generators; or issues in the coordination of generation and network investment - for example, in Germany, there are major grid constraints between the North and South due to the growth of renewable energy, and as a result additional capacity is required in the South pending network reinforcement.

For example, the Single Electricity Market (SEM) of Ireland, begun in 2007 , incorporated the previously separate markets of the Republic of Ireland (a sovereign nation) and Northern Ireland (a devolved region of the United Kingdom) into one centrally-cleared market, in order to maximize social welfare for the island of Ireland as a whole.

Historically, there was concern over the constituent markets of Ireland being sensitive to plant entry and exit due to the size of the overall system, with a single gas generator being able to tip the market from shortfall to long-term surplus. As a result of the concerns that an energy-only market would not guarantee generation adequacy, the regulators made the call for an explicit Capacity Payment Mechanism (CPM) to be a requirement of the SEM:

"We are concerned at the potential volatility of energy market prices, and recognise that a key challenge for a generator who wishes to enter the market is to convince prospective lenders that the investment risk can be evaluated, and that the risk is reasonably low....the intention for a CPM then, is for a mechanism providing for capacity adequacy through economic signals that are directly meaningful to investment decisions of 
generators and to the decisions of demand side participants. These economic signals should lead to socially efficient decisions on new investments, on maintenance of existing capacity and on demand response." (CER \& NIAUR, 2005)

The CPM was hence included in the SEM implementation, and designed to provide separate remuneration for capacity and so to limit volatility in energy prices, providing more stable signals for long-term investments in new capacity. Withdrawal of generation for maintenance is on a planned basis - it is in the interests of owners of plant to plan to withdraw when the plant is least needed, so that their loss of capacity payments and any profit on the market is minimised. The CPM is composed of 3 payments from differing timescales, providing both stable long-term ex-ante signals and shorter term volatile ex-post cashflows.

Similarly, in the Great Britain market, between 1990 and 2001, the 'Pool' was the mechanism in place for the GB electricity market, acting as a compulsory day-ahead last-price market, and included a capacity payment based on loss of load probability.

However, in the energy-only market introduced in GB under the New Electricity Trading Arrangements of 2001, the expectation was that capacity adequacy would be maintained by electricity prices rising if the market anticipates an impending shortage of capacity - the "peak load pricing theory". However, it has proven difficult for generators to base major capital investments on the basis of high prices in periods of supply scarcity due to operational (Linklaters, 2014), as well as the impact on market prices from increasing volumes of zero marginal cost renewable generation. There has hence been motivation to provide an additional revenue stream which may offset the failure to attract sufficient capital investment.

\subsection{Technical Drivers}

Technical drivers include reliability of ageing plant; increasing penetrations of near-zero marginal cost renewable generation; emissions caps restricting the operational lifetime of coal plant; and an inability to adequately predict future electricity demands.

In the electricity market of Great Britain described above, the early attractiveness of gas generation and slow growth in electricity demand helped to maintain adequate capacity margins after liberalisation in 1989, but the last decade has seen the margin eroded and confidence in capacity adequacy has reduced for several reasons (Newbery \& Grubb, 2014):

- Age and environmental legislation (particularly the EU Large Combustion Plant Directive and Industrial Emissions Directive) leading to widespread retirement of coal plants;

- Nuclear plants being retired at the end of their operational lifespans;

- Rising and volatile gas prices deterring new gas plant;

- A policy-driven uptake in renewable and intermittent low-carbon generation;

- Uncertain trends in electricity demand.

Figure 2 shows the reduction in capacity margin that has developed in recent years in the GB market, and the increase in wholesale price volatility that has occurred as a result due to scarcity pricing during periods of peak demand. As described, however, this pricing has failed to stimulate sufficient new investment in generation to prevent further reduction in security.
In order to tackle both the adequacy issue and the economic issues described above the UK Energy Act 2013 set out a package of legislation for the Electricity Market Reform (EMR), which includes long-term Contracts for Difference for low-carbon generation, and a Capacity Market - the first such to be in place since the Pool was replaced (DECC, 2016). The Capacity Market is an auction conducted annually for delivery of capacity in 4 years' time, with agreements lasting between 1 and 15 years. While interconnectors have been permitted to access the market and bid in capacity, conservative de-rating factors have been applied to reflect the level of dependence on the pre-requisite market conditions for the external markets to support the GB system at times of key stress (Pöyry, 2016).

Under similar constraints, a Capacity Mechanism has been implemented in Belgium since the winter of 2014/15 in response to multiple threats to generation adequacy (Hoschle, 2015):

- A planned phase-out of nuclear electricity begun in 2015;

- Unplanned technical outages of ageing nuclear plants;

- Mothballing of gas-fired generation units due to limited profitability.

Elia, the Transmission System Operator (TSO), is responsible for contracting 'Strategic Reserves' for each winter period, from a mixture of generation and demand response, based on their own adequacy forecasts, with contracts extending from one to three years. Generating units which are intending to leave the market (either from being shut down or mothballed) are obliged to submit an offer.

In Germany, the 'Energiewende' has led to a phase-out of nuclear and coal capacity in favour of renewable energy sources, with a growing cost of sourcing local flexibility and a constraint in terms of transmission capacity (Growitsch, Malischek, Nick, \& Wetzel, 2013). A new tenderbased capacity reserve will be implemented from 2017 which will only be open to generators not already part of the power market, in order to stimulate new build (Linklaters, 2015). It should be noted, however, that this is in parallel to a temporary 'security standby' payment to exiting carbon-intensive lignite generators (Clean Energy Wire, 2016). This intervention essentially leads to a rearrangement of the dispatch order where lignite plant would previously have formed a significant component of dispatched generation, here additional payments are made to reserve the use of such units for stress events and so reduce overall carbon emissions. In this way, the consumer cost and environmental aspects of the Trilemma are directly linked. In the German market, such an arrangement is seen as transitional with the intention being that the core energy market should in the long-term provide sufficient signals for investment once the low-carbon transition has been achieved. This highlights that some Capacity Mechanisms may be seen as a permanent requirement of a secure energy market, while other States may consider the underlying drivers to be temporary issues to be resolved.

\subsection{Political Drivers}

Political drivers are more complex to assess. The appropriate level of security of supply within a market may be politically determined based on what is perceived as an 'acceptable' level of security that may be in excess of the level economically determined by the Value of Lost Load. Secondly, volatility in power prices may be viewed as politically unsustainable - even where that volatility is providing a price signal to generation investment. There is also an assymetrical nature to the issue of setting the level of desired security against an uncertain background. 

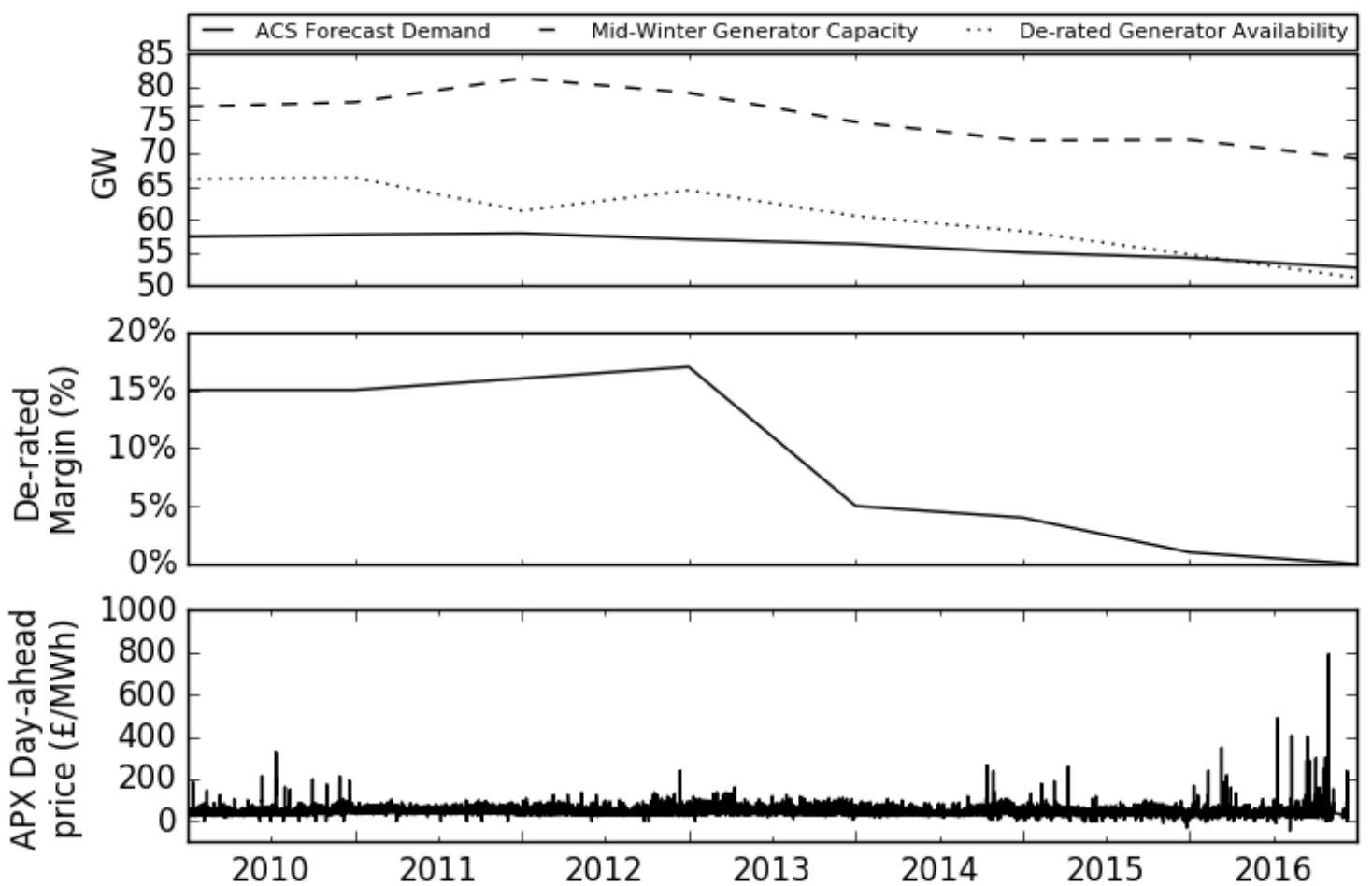

Figure 2 - The influence of capacity on electricity prices in the GB system. The top graph shows the declining level of installed capacity (not including Contingency Balancing Reserve procured outside the market) for each winter period as identified by the System Operator against the predicted Average Cold Spell (ACS) Demand. The de-rated availability adjusts the capacity level according to the ability of each generation type to be able to contribute to meeting peak demand. The middle graph shows the capacity margin (i.e. the excess of generation capacity over peak demand) that is given from the above capacity levels once interconnector contributions are considered. The bottom trace shows the day-ahead energy price in the APX power exchange, showing the increasing volatility in wholesale prices as the capacity margin has decreased. (APX Power Spot Exchange, 2016; National Grid, 2016)

A set of policies which leads to over-procurement of capacity results in a marginal increase in consumer's energy bills, whereas an underprocurement of capacity may entail customer disconnections or even black-outs, which clearly result in far more significant political consequences. This is supported by the historical tendency of centrally planned markets to over-procure capacity. The Portuguese capacity market was abolished in 2013 following concerns about overcapacity (Clean Energy Wire, 2015) - the additional cost placed on consumers was not seen as justifiable for the level of security gained. In this respect, separately from technical and economic considerations, as the costs of Capacity Mechanisms are borne by the end consumer, the conceptual side of electricity security - the ability for a consumer to 'trust' the delivery of electricity when and how they require it - must be sold to the nontechnical consumer at what is perceived to be a reasonable cost.

Similarly, the technical narrative around a potential supply gap can also be subject to non-technical interpretation. In the GB market in September 2016, the System Operator, National Grid renamed their 'Notice of Insufficient Margin' - a market notification system used to incentivise additional sources of capacity at key times - to a 'Electricity Margin Notice' (National Grid, 2016) in part in order to remove the implication that a failure of supply is likely to occur .

Additionally, due to the amount of change being enacted in Western Electricity Markets, the need for a Capacity Mechanism may also be driven by the uncertainties of the policy environment - one reason given for the recent downturn in capital investment in the GB market is the ongoing policy uncertainty that generators face (Linklaters, 2014), with recent governments publishing successive White Papers prioritising different aspects of the Trilemma and enacting market interventions driven by competing principles.

Another dimension is the political desire, external to the electricity sector, as to whether to pursue further integration with neighbouring states. The UK, for example, held a referendum on EU Membership in June 2016 which led to a stated intention to cease membership of the Union. While it is not clear at the time of writing if this will lead to changes in the interaction of the GB and Northern Irish markets with the EU Single Market for energy, this wider economic stance appears to prioritise independence from mainland Europe over other concerns.

In all of the economic and technical examples given in this section there is a political dimension to the Capacity Mechanism implementation, in that the Mechanism exists to facilitate a broader strategy in the supply of electricity - be that the liberalisation of markets and the removal of central planning; a response to trends in the composition of generation sources (and a desire to hedge risk by having a diverse energy supply base); or in order to facilitate a growing penetration of inflexible and intermittent renewable energy sources which may negatively influence total system security. In this respect the enacting of a Capacity Market can 
be seen as an interventionist tool which permits the government or its agencies to manually adjust their position on the Trilemma, as such a mechanism allows the rebalancing of cost versus security of supply while directly influencing a market's capacity for low carbon electricity sources.

\section{Impacts of Capacity Mechanisms on cross-border trade}

There are two types of cross-border distortions in markets resulting from local capacity mechanisms (Hancher et al., 2015). Firstly, static short-term distortions affect whether prices reflect the cost of production and hence whether the production of electricity is least-cost effective. If a capacity mechanism does not adequately consider non-domestic generation capacity, then wholesale distortions will arise. If a generator receives payments which affect their electricity generation bids into the market, and generators in a neighbouring energy-only market do not receive such payments, then this will alter the ability of generators in neighbouring markets to directly compete on price.

Secondly, there may be dynamic distortions which impact generation investment decisions. Capacity mechanisms may even become the main driver for investments in new electricity generation capacity, rather than energy prices, as has been demonstrated in modelling of the potential impact of a capacity mechanism in the German market (Ozdemir, De Joode, Koutstaal, \& Van Hout, 2013).

Other cross-border effects have also been identified (Meyer \& Gore, 2015):

- A decrease in peak prices, due to a solely energy-based remuneration being replaced with two-part payments to generators for energy and capacity, meaning that the 'missing money' problem (where market prices do not adequately represent scarcity value and so are insufficient to stimulate investment in new-build capacity) may be in part exported as generators in neighbouring markets cannot benefit from price spikes in the market with the Capacity Mechanism;

- Impacts on capacity, due to additional investments being triggered in regions with a Capacity Mechanism at the possible expense of investment decisions in neighbouring markets;

- Impacts on welfare, whereby an increase in generation capacity in a market with a Capacity Mechanism leads to a smaller increase in available capacity in a neighbouring market due to their interconnection, despite consumers in the second market not having to pay for that capacity;

- A reduction in infrastructure investment due to reduced trade leading to lower congestion rents;

- A redistribution of economic surpluses between generators and consumers (i.e. reduced or increased profit for investors) leading to a possible decrease in total welfare.

Because a country has no control over generation at the other end of an interconnector there has been a default methodology which assumes that interconnectors do not make any contribution to national security of supply (Newbery \& Grubb, 2014).

There are 3 main determinants of a shortfall of capacity in western European markets: the level of peak demand, failures of conventional plant, and the availability of intermittent generation. The chances that each of these could occur simultaneously in two or more neighbouring countries is hence low, and the role of interconnection is enhanced by the market coupling increasing responsiveness of flows to price differentials, so that imports should occur through cross-border signals in response to all but very short-term fluctuations.

\section{EU Regulation of Capacity Mechanisms}

The EU approach to capacity mechanisms has varied across legislative packages. In April 2015, in response to the growth in national capacity mechanisms, the European Commission launched a state aid inquiry into their use, in order to determine whether they ensure sufficient electricity supply without distorting competition and trade in the Single Market. Such mechanisms are permitted when "there is a real risk of insufficient electricity generation capacity" (European Commission, 2014) in order to encourage new generation capacity, postpone closures of existing plant, or reward consumers for actions which lead to reductions in peak consumption. Design of such a mechanism, in addition to generic competition and market stipulations, is required to consider:

- A clear demonstration of the reasons why the market cannot be expected to deliver adequate capacity in the absence of intervention;

- A description of the unit of measure for quantification of security and its method of calculation;

- Assessment of the impact of variable generation (including in neighbouring systems), demand-side participation, and interconnectors;

- A remuneration only for availability: that is, a payment made per unit of power committed to be available, and not per unit of energy sold;

- Adequate incentives to existing and future generators and allow for potentially different lead times for different technologies, and be open to potential aggregation of both demand and supply;

- The ability for operators from other Member States to participate where it is physically possible for them to do so.

Additionally, the mechanism should not reduce incentives to invest in interconnection capacity, undermine market coupling, strengthen market dominance, undermine pre-existing investment decisions or give preference to low-carbon generators with equivalent technical and economic parameters (that is, the mechanism should be distinct and separate from one designed to decrease the carbon intensity of generation). It should be noted that many extant mechanisms do not abide by the above requirements, and there is a distinction to be made between mechanisms which have developed to date in a relatively unregulated manner and those under consideration and implementation today.

A sector enquiry by the European Commission found that two-thirds of such mechanisms are through targeted means, although mechanisms currently in planning tend towards market-driven designs (European Commission, 2016). Concerns have been raised that many technologies are often omitted from mechanism designs, and that only 3 markets (Belgium, Germany and Ireland) explicitly permit direct participation of cross-border capacity. It is also noted that 'almost half of the Member States studied appear not to have adequately established what should be their appropriate level of supply security before putting in place a capacity mechanism', which may further distort investment as generators will not be capable of appropriately predicting future capacity procurement levels. Ongoing assessment of capacity mechanisms will be conducted on a caseby-case basis by the European Commission, reflecting individual Member State requirements. 


\section{Routes to reconciliation}

The ongoing conflict between national/regional capacity mechanisms and the goals of a single European energy market may be addressed by a number of potential mechanisms, each of which carry a number of regulatory challenges:

\subsection{Incorporation of interconnection capacity into national mechanisms}

Firstly, the actual cross-border exchange of capacity could be permitted that is, generators in neighbouring markets are allowed to bid for capacity within the mechanism. This would ensure the competitive benefits of cross-border trading in energy are extended into capacity, and reduce overall costs. However, this would introduce several complexities - a mechanism would be required to assess and certify foreign capacity and to determine its effective contribution taking into account transmission constraints, and to ensure that the foreign capacity is making the same effective provision as local participants. Further, the generation capacity would need to be matched by a firm transmission capacity across the interconnector. It would also be necessary to ensure that there were no other market distortions present between the markets. In the specific case of Great Britain, a carbon price floor contributes to wholesale prices being significantly higher than in continental Europe. Network charging, renewable subsidies and taxation of generation and supply would also need to be harmonised to prevent distortions.

If a proportion of cross-border transmission capacity is reserved for this purpose, then this would limit the efficiency of cross-border energy trading. If the generator is instead required to purchase transmission rights to demonstrate an ability to deliver capacity, then while this would be more compatible with the EU target model for capacity allocation, this could lead to netted flows being inverted where both markets are capacity scarce and the provision of capacity is in opposition to the flow of traded energy. Similarly, the requirement to provide matched transmission capacity with generation capacity could be ignored under the assumption that cross-border flows are optimised, and prices should reflect scarcity, ensuring the flow is in the correct direction, but this may not occur under all conditions and would be dependent on Capacity Mechanisms between neighbouring countries being aligned. If capacity allocation is ignored, then there is no effective improvement upon the current methodology of taking into account the statistical contribution of interconnection rather than considering particular foreign generators - indeed, under such a mechanism where the transmission capacity is determined by the pricebased flow, a foreign generator not participating in the Mechanism would be contributing to security of supply as much as one which was participating.

In addition, if a generator is able to access neighbouring markets, then they may be able to simultaneously bid capacity into more than one market. This could prove problematic if that generator is called to deliver in more than one market simultaneously. This could be removed via appropriate regulation, or alternatively viewed as a risk by the market operator which can be ameliorated through the use of de-rated capacities, similar to the current treatment of interconnectors in the Great Britain Capacity Auction. Similarly, there is the question of whether transmission rights in the future purchased by a generator in one market entitles it to access the entire harmonised EU transmission system or only their domestic market - should the market harmonisation extend to the point where interconnectors are treated equitably as elements of the transmission network rather than separate entities with separate access rights?

Expanding the terms of the auction to include cross-border participation would not, however, address the issue that differing incentives between markets could lead to an implicit competition of national Capacity Mechanisms among each other, which may shift the generation mix away from the optimum, if viewed at a pan-European level (Hoschle, 2015). Clearly, then, the value of interconnection needs to be recognised within a national capacity mechanism in order to avoid overprocurement of local capacity at significant cost to the consumer, but the question remains of the optimal methodology for harmonising interconnection with a capacity mechanism to avoid distortions in crossborder energy trading. Increasing transmission capacity under asymmetric market designs may even serve to magnify existing distortions (Cepeda \& Finon, 2011).

\subsection{A single Capacity Market design}

A second approach would be to harmonise and coordinate national capacity mechanisms under a single design. However, with many different Capacity Mechanisms already in place, others being implemented, and a difference in generation backgrounds creating different drivers for design of those mechanisms, it seems unlikely that a single design would be appropriate across all Member States. The main drivers and objectives of Capacity Mechanisms vary between states, so it is unlikely that a 'onesize fits all' approach would work. It does not appear that such a common design is a current focus of the EU Commission. Local market designs may also reflect local physical adequacy in a more efficient manner.

\subsection{A single EU-wide Capacity Market}

Taking this idea further, a single EU-wide capacity mechanism could be enacted, as capacity installed solely to cope with scarcity in each individual market area leads to overcapacity seen in the European context. In (Neuhoff et al., 2013), a nodal pricing market design across Europe is proposed (similar to that currently enacted within NordPool), where security is shifted away from regional operators (TSOs) towards centralised management. This approach appears to lead to an increase in transfers between countries due to more efficient use of interconnection capacity, but would obviously entail major institutional changes. However, systemic deviations away from the reference price at a node would provide a clear locational signal for power plant investment, in principle obviating the long-term need for separate capacity payments.

The European Network of Transmission System Operators for Electricity (ENTSO-E) does not advocate a radical change in the governance framework for security of supply in Europe, but proposes that national markets integrate in a local manner (ENTSO-E, 2015). Eurelectric, the association representing the European electricity industry, has proposed a roadmap to a European capacity market in which the development of national Capacity Mechanisms, and their regional coordination, form the interim steps over the next decade (Eurelectric, 2015). However, there remains a wider question over whether Capacity Mechanisms will endure as an appropriate means of tackling the growing question of security of supply against the aims of decarbonisation and, if the energy-only market is currently incapable of delivering adequate capacity, whether more fundamental redesign of European electricity markets - capable of incorporating new sources of flexibility and 
reliability - may provide a more efficient solution (Gottstein \& Skillings, 2012).

\subsection{Alternative instruments}

An alternative view of the adequacy problem in modern-day electricity markets is that a perceived absence of capacity is not the core issue; rather, it is that flexibility of generation (such as by thermal plant ramping output to match a shortfall in renewable generation) is undervalued in modern markets, and may be further undervalued where Capacity Mechanisms are in use (RAP Energy Solutions, 2012). In a Capacity Mechanism which is technology-neutral, qualifying generators are not incentivised to provide maximum flexibility. In this regard, alternative measures which directly remunerate flexibility on a technology-neutral basis are likely to be better suited to managing increasing levels of renewable generation in European markets.

A second set of instruments which help to address the capacity issue are risk hedging products, which do not currently exist in all European markets (ENTSO-E, 2014), and may be traded across interconnectors in order to provide an additional signal for generation investment. This allows market participants to trade cross-border capacity and hedge against price fluctuations. This allows increased risk management by market participants, in turn incentivising increased trade volumes.

\section{Conclusion}

The implementation of Capacity Mechanisms in a number of EU Member States is threatening to distort the efficient flow-based price signals of the European Internal Electricity Market. The to-date regional view of electricity security prefers ongoing self-sufficiency over mutual security, even though this comes at a greater cost. However, as the drivers between countries for those Capacity Mechanisms are often similar, there is little perception that neighbouring European countries can or should rely on one another during periods of maximum system stress, which may be coincident across borders. It appears clear that scarcity pricing from energy-only markets will be insufficient to reassure national governments that their electricity system will remain secure in the long run. The trajectory towards decarbonisation in the EU will only continue to exacerbate this situation as the need for flexible sources of generation (to balance intermittent renewables) grows over time.

It is not necessarily the case, however, that the choice between scarcity pricing and Capacity Mechanisms is a binary one, and that the latter must necessarily distort the former. If a Capacity Mechanism is based solely on availability rather than actual physical injections of electricity, then there is no effect on the spot market in terms of short-term dispatch. The effects are, instead, in the long-term, by affecting the generation mix, and this may be less significant than other national policies, such as through renewable generation incentives, carbon pricing or direct interventions into generation investment as a result of external government policies such as trade deals or wider economic planning. Similarly the Capacity Mechanism may be used as a policy instrument to enact a desired balance within the Energy Trilemma of security, environmental impacts, and costs to consumers.

While each national Mechanism has been driven by a set of issues particular to that market, many of those issues are present - or starting to develop - simultaneously in multple EU markets. An EU-wide approach is required which addresses these root causes in a manner that safeguards the efficient trade of electricity sought through the Third Energy Package, while providing sufficient signals to new investment in both generation and transmission. This may involve the use of Capacity Mechanisms as a stepping-stone towards risk sharing and hedging instruments that are active across borders, or it may continue to incorporate Capacity Mechanisms as a long-term solution, albeit with appropriate regulation in place to avoid distortions in cross-border trade.

\section{Acknowledgements}

This research was undertaken within the UK Energy Research Centre (UKERC), supported by the UK Research Councils under Natural Environment Research Council award NE/ G007748/1 and EPSRC Grant No. EP/L024756/1.

\section{REFERENCES}

Ang, B. W., Choong, W. L., \& Ng, T. S. (2015). Energy security: Definitions, dimensions and indexes. Renewable and Sustainable Energy Reviews, 42, 1077-1093.

Cepeda, M., \& Finon, D. (2011). Generation capacity adequacy in interdependent electricity markets. Energy Policy, 39(6), 31283143.

CER \& NIAUR. (2005). Capacity Payment Mechanism Options Paper. Ciuta, F., \& Ciută, F. (2010). Conceptual Notes on Energy Security: Total or Banal Security? Security Dialogue, 41(2), 123-144.

Clean Energy Wire. (2015). Capacity markets around the world. Clean Energy Wire. (2016). Germany's new power market design. DECC. (2016). The Capacity Market (Amendment) Rules 2016.

ENTSO-E. (2014). ENTSO-E Overview of Internal Electricity Marketrelated project work.

ENTSO-E. (2015). Cross-Border Participation to Capacity Mechanisms. ENTSO-E. (2016). Transparency platform: cross-border physical flow. Eurelectric. (2015). A reference model for European capacity markets. European Commission. (2014). Guidelines on State aid for environmental protection and energy 2014-2020. Official Journal of the European Union, C 200/1.

European Commission. (2015a). A Framework Strategy for a Resilient Energy Union with a Forward-Looking Climate Change Policy.

European Commission. (2015b). State Aid: sector inquiry into capacity mechanisms.

European Commission. (2016). State aid: interim report of sector inquiry on electricity capacity mechanisms shows significant shortcomings.

European Parliament. Directive 2009/72/EC (2009).

Gottstein, M., \& Skillings, S. A. (2012). Beyond capacity markets Delivering capability resources to Europe's decarbonised power system. In 9th International Conference on the European Energy Market. Florence, Italy.

Growitsch, C., Malischek, R., Nick, S., \& Wetzel, H. (2013). The Costs of Power Interruptions in Germany - an Assessment in the Light of the Energiewende. EWI Working Paper, (7).

Hancher, L., de Hauteclocque, A., \& Sadowska, M. (2015). Capacity Mechanisms in the EU Energy Market: Law, Policy, and Economics. book, OUP Oxford.

Helm, D. (2004). The New Regulatory Agenda. The Social Market 
Foundation.

Hoschle, H. (2015). Capacity Remuneration Mechanisms Implementations in Europe and Implications for the European Internal Energy Market. CIGRE International Symposium - HVDC Systems and Market Integration.

Jacottet, A. (2012). Cross-border electricity interconnections for a wellfunctioning EU Internal Electricity Market. Oxford Energy Comment, (June), 1-17.

Jervis, R. (1978). Cooperation under the Security Dilemma. World Politics, 30(2), 167-214.

Keay, M. (2013). The EU “Target Model” for electricity markets: fit for purpose? Oxford Energy Comment, (May), 1-11.

Li, X. (2005). Diversification and localization of energy systems for sustainable development and energy security. Energy Policy, 33(17), 2237-2243.

Linklaters. (2014). Capacity Mechanisms: Reigniting Europe's Energy Markets.

Linklaters. (2015). Germany : New electricity market design ahead.

McGowan, F. (2008). Can the European Union's Market Liberalism Ensure Energy Security in a Time of "Economic Nationalism"? Journal of Contemporary European Research, 4(2), 90-106.

Meyer, R., \& Gore, O. (2015). Cross-border effects of capacity mechanisms: Do uncoordinated market design changes contradict the goals of the European market integration? Energy Economics, $51,9-20$.

National Grid. (2016). Winter Outlook Report 2016/17.

Neuhoff, K., Barquin, J., Bialek, J. W., Boyd, R., Dent, C. J., Echavarren,
F., ... Weigt, H. (2013). Renewable electric energy integration: Quantifying the value of design of markets for international transmission capacity. Energy Economics, 40, 760-772.

Newbery, D. (1989). Missing markets: consequences and remedies. In F. H. Hahn (Ed.), Economics of Missing Markets, Information, and Games (pp. 211-42). Oxford: Clarendon Press.

Newbery, D. (2015). Missing money and missing markets: Reliability, capacity auctions and interconnectors. Energy Policy, (February 2015).

Newbery, D., \& Grubb, M. (2014). The Final Hurdle?: Security of supply, the Capacity Mechanism and the role of interconnectors. Cambridge Working Paper in Economics, 1433, 1-29.

Ozdemir, O., De Joode, J., Koutstaal, P., \& Van Hout, M. (2013). Financing investment in new electricity generation capacity: The impact of a German capacity market on Northwest Europe. In 10th International Conference on the European Energy Market. Stockholm, Sweden.

Pöyry. (2016). Costs and benefits of GB interconnection.

RAP Energy Solutions. (2012). What Lies "Beyond Capacity Markets”? Delivering least-cost reliability under the New Resource Paradigm.

RAP Energy Solutions. (2013). Capacity Mechanisms For Power System Reliability, (October).

Tang, S. (2009). The Security Dilemma: A Conceptual Analysis. Security Studies, 18(3), 587-623.

Turvey, R. (2006). Interconnector economics. Energy Policy, 34(13), $1457-1472$. 